\title{
A Resistência escrava revisitada: a espacialidade como elemento central
}

\author{
Fernando Antonio Alves da Costa \\ Doutor em História Econômica pelo PPGHE da FFLCH-USP \\ faacosta@usp.br
}

Resenha de: SANTOS, Marco Aurélio dos. Geografia da escravidão no Vale do Paraíba cafeeiro: Bananal, 1850-1888. São Paulo: Alameda Editorial, 2016.

Geografia da escravidão no Vale do Paraíba cafeeiro: Bananal, 1850-1888, do historiador Marco Aurélio dos Santos, é mais uma das recentes contribuições para a historiografia brasileira que estuda a escravidão. Originário da tese de doutorado do autor, defendida no ano de 2014 no Programa de Pós-Graduação em História Social da Universidade de São Paulo, o trabalho revisita temas clássicos do debate acerca do passado escravista brasileiro. Autonomia escrava, roças cultivadas pelos cativos, formação de comunidades solidárias que uniam escravizados na luta contra as agruras do cativeiro e, em sentido mais geral, a oposição entre possibilidades e constrangimentos estruturais para a agência escrava são alguns dos aspectos retomados pelo historiador e que perpassam o texto.

O município de Bananal já foi bastante estudado, visto que se constituiu em um dos principais produtores de café do Brasil das primeiras décadas do século XIX. ${ }^{1}$ No decênio de 1850 a localidade pas-

\footnotetext{
1 Marco Aurélio dos Santos dialoga com vários trabalhos sobre a localidade. A título de exemplo da produção historiográfica que privilegiou o recorte espacial de Bananal, somente no âmbito da história demográfica dois importantes trabalhos que abordaram a localidade em diferentes momentos do desenvolvimento da lavoura cafeeira foram: MOTTA, José Flávio. Corpos escravos,
} 
sou a ser a maior produtora de café da província de São Paulo, tendo alcançado o ápice de sua produção na década seguinte. A participação dos escravizados na composição total da população da localidade foi a maior entre os principais municípios do Vale do Paraíba Paulista, alcançando percentual de 53\% (p. 35-37). Dessa forma, a chegada da rubiácea na região alterou profundamente a demografia da localidade. As relações sociais e políticas, pautadas pelas assimetrias características do escravismo, também sofreram mudanças drásticas em curto espaço de tempo. Isso sem mencionar toda a carga cultural trazida pelas levas de africanos introduzidos abruptamente na região via tráfico internacional ou interno de escravos.

O recorte cronológico privilegiado pelo autor é outro ponto bastante recorrente na historiografia da escravidão, na medida em que suas balizas marcam dois momentos centrais do passado escravista brasileiro. O livro aborda o intervalo temporal compreendido entre o final do tráfico internacional de escravos (1850) e o colapso da escravidão no Brasil (1888).

Se os pontos acima destacados, recortes geográfico e cronológico, não são propriamente inovadores, Marco Aurélio dos Santos agrega ao debate sobre escravidão e resistência cativa o estudo do elemento espaço. Mais precisamente, o autor estuda a espacialidade das fazendas cafeeiras escravistas. Por espacialidade entende a soma da cultura material (espaço material), das relações sociais (espaço social) e das interpretações e apropriações dos espaços (espaço cognitivo). (p. 26-28).

Subsidiado pela concepção acima, o argumento central que o autor sustenta é que, a um só tempo, o espaço agrário das zonas de produção cafeeira constituiu-se tanto em instrumento de dominação senhorial como em estratégia para resistência escrava. No primeiro sentido os senhores escravistas pensaram e utilizaram a espacialidade

vontades livres: posse de cativos e família escrava no Brasil (1801-1829). São Paulo: Fapesp, Annablume, 1999. MORENO, Breno Aparecido Servidone. Demografia e trabalho escravo nas propriedades rurais cafeeiras de Bananal, 1830-1860. Dissertação (Mestrado em História Social) $\square$ FFLCH/USP, São Paulo, 2013. 
como mecanismo de imposição e de facilitação da ordem. No segundo viés os espaços foram ressignificados pelos cativos, que fizeram usos alternativos diferentes daqueles para os quais foram projetados. É fundamental para o entendimento do argumento a concepção, explicitada desde a introdução do trabalho e frequentemente retomada pelo autor, de que os espaços não são estáticos nem neutros. Muito pelo contrário, ganham sentido e significado por meio dos usos que os seres humanos fazem deles. Dessa forma, a espacialidade é entendida como somatória dos diversos espaços e como campo de ação. No caso em questão das fazendas de produção cafeeira de Bananal, puderam servir tanto para dominar quanto para resistir, a depender das intencionalidades dos indivíduos que atuaram e que interagiram com os espaços (p.21-28).

Marco Aurélio dos Santos construiu seu objeto de pesquisa proposto - a utilização plural dos espaços agrários de Bananal - primordialmente por via de uma série de processos criminais que envolveram cativos, independentemente da forma como apareceram: réus, vítimas, informantes ou testemunhas. Foram utilizados 146 processos distribuídos de forma desigual pelas décadas contempladas, com prejuízo para o decênio 1850, com apenas 4 processos. ${ }^{2}$ Embora tenha trabalhado com documentação criminal, os crimes propriamente ditos não foram o aspecto central objeto da atenção do autor. A leitura e análise das fontes focou a interação dos personagens com a espacialidade: "A criminalidade de escravos e homens livres terá interesse apenas circunstancial. Partindo do par de conceitos controle/resistência, realizou-se uma leitura das fontes documentais que priorizou a análise da ação dos sujeitos no espaço" (p. 24).

Geografia da Escravidão está organizado em 3 capítulos, muito bem demarcados e antecedidos por uma consistente introdução na qual o autor apresenta e discute seus pressupostos teóricos, suas fontes

2 Conforme mencionado, a série de processos criminais constitui a fonte principal da pesquisa. De forma episódica foram utilizados pelo autor outras fontes: 27 inventários post-mortem, Códigos de Postura da Câmara Municipal de Bananal (1865 e 1886), livro do Fundo para Emancipação de escravos, ofícios diversos, Livro de Casamento de escravos, periódicos, relatos de viajante etc. 
e metodologia, com as ressalvas feitas acima, seus objetivos e argumentos centrais e específicos. Finaliza a introdução um breve histórico da localidade de Bananal no período selecionado, justificando os recortes temporais e espaciais da pesquisa.

No primeiro capítulo Marco Aurélio dos Santos se dedica ao estudo da espacialidade pelo viés dos proprietários escravistas, a geografia senhorial. Toda a constituição da arquitetura das fazendas cafeiculturas fora pensada com o intuito de favorecer o controle, a ordem, a otimização da produção, a fiscalização e a redução da mobilidade dos cativos. O livro traz no capítulo imagens e fotografias que contribuem para a argumentação do autor. Via de regra, as fazendas eram projetadas em quadriláteros funcionais que objetivavam o controle sobre o interior do quadrado. Todos os edifícios (senzalas, casas de vivenda e espaços de armazenamento e beneficiamento da produção) ficavam dispostos em quadra. Os demais espaços que as fazendas continham também seguiam o mesmo propósito de controle e disciplina: a enfermaria sempre trancada e de acesso restrito, o portão da fazenda que delimitava o espaço de mobilidade dos escravizados, o sino que disciplinava o tempo, as roupas que caracterizavam a condição cativa, os investimentos dos senhores sobre o corpo dos escravos (ferros no pescoço, por exemplo) contribuíram para a composição da geografia senhorial. $\mathrm{O}$ autor argumenta ainda que nos espaços públicos fora das fazendas, a movimentação e o tempo dos escravos eram disciplinados pelos Códigos de Posturas Municipais. A mecânica do funcionamento de todo este aparato foi percebida nos processos criminais utilizados.

No segundo capítulo, Marco Aurélio dos Santos destaca a noção de vizinhança como espaço social paulatinamente construído e como ação social articulada em espaço mais amplo, para além das fazendas. Importante também a abordagem ampliada sobre as redes de relacionamentos constituídas pelos escravizados. Durante muito tempo vistas pela historiografia como sinônimo de solidariedade, Marco Aurélio dos Santos amplia o olhar sobre as redes de relacionamentos entre os escravos. A solidariedade poderia ser apenas uma das possibilidades. No entanto, não raramente, as redes congregavam elementos contraditórios e foram também potencialmente conflituosas. $\mathrm{O}$ autor 
cita eventos que ilustram as possibilidades de mobilidade dos escravos, algumas consentidas pelos senhores, outras não. Constituíam assim redes de relacionamentos com escravizados de outros plantéis, passavam por caminhos que cruzavam outras fazendas e se relacionavam com homens livres, alforriados, comerciantes e demais personagens do mundo agrário e urbano da localidade de Bananal no período analisado.

No último capítulo de Geografia da Escravidão, Marco Aurélio dos Santos lança mão de forma mais abundante da documentação para estudar a "geografia dos escravos", composta de usos alternativos dos espaços de plantação e do tempo. São vários os casos relatados de escravos que se apropriaram de uma espacialidade aparentemente hostil para encontrar alternativas para suavizar, resistir e até mesmo questionar a condição servil. Bastante elucidativo é o caso do escravo Constantino, cativo de Braz Barboza da Silva. Constantino foi libertado pelo Fundo de Emancipação em 1883. Porém, o senhor omitiu-lhe a informação. O detalhe interessante é que Constantino tinha mobilidade consentida para fora dos limites da fazenda para realizar tarefas demandas por seu senhor. Em uma dessas andanças ficou sabendo da própria ao entrar em contato com um indivíduo livre. O caso exemplifica uma das formas de lidar com a espacialidade projetada para controle e disciplina. Nas palavras do autor "Malgrado o funcionamento rotineiro da mecânica do poder senhorial, foi possível perceber que os escravos construíram uma geografia própria a partir dos conhecimentos de suas movimentações autorizadas para além do espaço de plantação" (p.30). O capítulo ainda aborda as fugas do cativeiro, definindo-as como o momento mais emblemático dos usos alternativos dos espaços de plantação. Não obstante a eficácia da geografia senhorial por todos os seus aparatos disciplinares, o capítulo demonstra claramente que os recursos para controlar e disciplinar os cativos não foram suficientes para conter movimentações e usos alternativos pelos próprios cativos.

Talvez caibam duas ponderações sobre a forma como Marco Aurélio dos Santos apresenta as fontes selecionadas. A primeira, de ordem metodológica e a segunda, de estética. A documentação utilizada não é alvo de uma apreciação crítica, visto que o autor não discute seus limites e possibilidades. Algumas reflexões seriam pertinentes. Por 
exemplo: quais os contextos de produção da documentação? Os escravos falam por si mesmo ou têm representantes? Quem eles seriam e quais suas intencionalidades? Em que medida tomar a utilização da espacialidade por meio dos processos criminais é representativo do cenário que o autor buscou retratar? Trazer para o texto essas e outras questões, que muito provavelmente acometeram o autor em algum momento da pesquisa, não invalidariam de forma nenhuma os resultados do trabalho. Somente lançariam luz sobre os limites e as possibilidades que o historiador encontra na relação com o passado e com seu objeto de pesquisa, além de esclarecer os métodos empregados.

Outra ponderação importante diz respeito à organização do trabalho. A forma como Marco Aurélio dos Santos optou por estruturar a narrativa deixa os capítulos compartimentados, talvez excessivamente esquemáticos. As partes acabaram por ser tornar demasiadamente estanques. O primeiro capítulo trata da espacialidade do ponto de vista senhorial, ao passo que o terceiro o faz da perspectiva dos cativos. Caso o autor tivesse feito uma opção mais dialógica, o texto se tornaria mais fluído, dinâmico e, principalmente, mais condizente com a realidade dialética que se propôs abordar, visto que os embates entre a geografia senhorial e a geografia escrava se davam de forma imbricada e emaranhada, não em tempos e formas separadas. Por mais que tenha sido uma opção didática perfeitamente compreensível, a organização do livro torna os capítulos 1 e 3 completamente independentes um do outro.

Um último ponto que causa estranheza no texto de Marco $\mathrm{Au}-$ rélio dos Santos é a ausência de uma discussão que tem sido bastante recorrente e profícua entre os pesquisadores da escravidão que tomam por base o trabalho de Dale Tomich. ${ }^{3}$ Este autor considera que a es-

3 Embora o autor cite entre suas referências bibliográficas um dos trabalhos de Tomich na versão em língua inglesa e mencione o conceito na página 19 da introdução, a discussão sobre a Segunda Escravidão está ausente do texto, bem como a referência a versão em português do livro do autor. TOMICH, Dale W. Pelo Prisma da Escravidão: Trabalho, Capital e Economia Mundial. São Paulo: Editora da Universidade de São Paulo, 2011. 
cravidão e o tráfico atlântico do século XIX não foram meras continuidades dos séculos anteriores. Nos Oitocentos assumiram características diversas, constituindo na verdade uma Segunda Escravidão. O trabalho cativo teria se reconfigurado de modo ainda mais potente, em alinhamento com a nova fase de desenvolvimento da economia mundial, sob égide da hegemonia britânica. Algumas das características apontadas por Tomich nessa nova fase das relações escravistas guardam íntima relação com o objeto de pesquisa proposto em Geografia da Escravidão. Entre outros elementos, a dinâmica peculiar do século XIX foi trazida pela expansão de zonas produtoras de artigos tropicais que tinham elevada e crescente demanda nos países centrais da Europa e nos EUA: o café (com grande participação da produção brasileira), o algodão e o açúcar. Ao negligenciar estranhamente esta discussão, visto que o autor dialoga frequentemente com historiadores que levam em conta as formulações de Tomich ${ }^{4}$, o livro deixa de incorporar e conectar seu objeto de pesquisa com dinâmicas mais amplas da política e das relações internacionais, exercício recente e profícuo entre os pesquisadores da escravidão.

No entanto, transcorridas as páginas de Geografia da Escravidão, fica a certeza de que o autor cumpriu muito bem a árdua tarefa de trazer novos e originais elementos para um dos mais ricos debates da historiografia brasileira.

\section{Bibliografia}

BERBEL, M., MARQUESE, R. B. e PARRON, T. Escravidão e política: Brasil e Cuba, 1790-1850. São Paulo: Hucitec, 2011. MARQUESE, R. B.; SALLES, (orgs.). Escravidão e Capitalismo Histórico no Século XIX. Rio de Janeiro: Civilização Brasileira, 2016.

4 Por exemplo: BERBEL, M., MARQUESE, R. B. e PARRON, T. Escravidão e política: Brasil e Cuba, 1790-1850. São Paulo: Hucitec, 2011. MARQUESE, R. B.; SALLES, (orgs.). Escravidão e Capitalismo Histórico no Século XIX. Rio de Janeiro: Civilização Brasileira, 2016. 
MORENO, Breno Aparecido Servidone. Demografia e trabalho escravo nas propriedades rurais cafeeiras de Bananal,1830-1860. Dissertação (Mestrado em História Social) - FFLCH/USP, São Paulo, 2013.

MOTTA, José Flávio. Corpos escravos, vontades liores: posse de cativos e família escrava no Brasil (1801-1829). São Paulo: Fapesp, Annablume, 1999.

TOMICH, Dale W. Pelo Prisma da Escravidão: Trabalho, Capital e Economia Mundial. São Paulo: Editora da Universidade de São Paulo, 2011.

Recebido: 10/01/2018 - Aprovado: 30/03/2018 